\title{
An Exploratory Survey in Collaborative Software in a Graduate Course in Automatic Identification and Data Capture
}

\author{
Stephen Elliott \\ Purdue University, \\ West Lafayette, IN, USA
}

elliott@purdue.edu

\author{
Teresa Rishel \\ Kent State University, \\ Kent, $\mathrm{OH}$
}

trishel@kent.edu

\begin{abstract}
TECH 621 is a graduate level course in Automatic Identification and Data Capture at Purdue University in West Lafayette, Indiana. Typically, it is offered to a cohort of students in a weekend masters program. The course meets on campus three times a semester for two four-hour periods; the course is updated each semester. In the fall of 2006, the instructor decided to incorporate a project component in the course that would show first semester graduate students the potential research opportunities available to them. However, in the planning phase of the projects, the scope grew, and one project took on an international component (with one group working with a university in South Korea), and the others involved working with on-campus undergraduate students. Thus, there was a need to manage the communication of all individuals involved, to provide it in the cheapest possible way, and to make sure that the technology did not fail and hinder the progress of the projects. Furthermore, a collaborative working environment was needed so that each student's contribution could be monitored. There was also a need to make sure that individual's didn't work on different document versions. This paper explains the process of choosing the appropriate technology, its limitations, and the results of student opinions of the technology. It provides a framework for further examination of on-line collaborative tools and study in this area. Important to the course development was determining effective and appropriate pedagogy to meet student needs.
\end{abstract}

Keywords: distance learning, collaboration

\section{Introduction}

Teaching a course remotely will always have challenges associated with it. These challenges typically do not arise from the students' comprehension of the materials, rather the technology used to deliver the course; communication with the instructor; and the "loneliness" of the independent distance student. Research on distance learning has evolved as much as the technologies

Material published as part of this publication, either on-line or in print, is copyrighted by the Informing Science Institute. Permission to make digital or paper copy of part or all of these works for personal or classroom use is granted without fee provided that the copies are not made or distributed for profit or commercial advantage AND that copies 1) bear this notice in full and 2) give the full citation on the first page. It is permissible to abstract these works so long as credit is given. To copy in all other cases or to republish or to post on a server or to redistribute to lists requires specific permission and payment of a fee. Contact Publisher@InformingScience.org to request redistribution permission. used. While much research has focused mainly on effectiveness of the technologies, current research includes a specific focus on how distance education students learn best. When technology is included as part, but not exclusive to the design of the course, and "adapted for the current environment, it can enable and support enhanced forms of learning" (Kirkwood \& Price, 2006, p.1). Thus, the instructor must choose technologies 
that not only enhance learning, but increase learner satisfaction, comfort, and adaptability, significant determinants of the effectiveness of a course (Simonson, Smaldino, Albright, \& Zvacek, 2003). The technological base of a distance education course should reinforce course goals, student needs, and desired learning. Improvements to distance education courses can be done through adjusting and refocusing instruction, not simply by adding new technologies. Bates (1995) points out that, "Good teaching may overcome a poor choice in the use of technology, but technology will never save poor teaching; usually it makes it worse" (p. 8).

Research by Garland (1993) on student barriers to persistence in distance education include those related to situational (learning environment, time management, support), institutional (costs, procedures, scheduling), and dispositional and epistemological factors. Among these, student success falls largely within dispositional and epistemological factors, which are those related to the student's "psychological and sociological nature" (Simonson et al, 2003, p. 69). Examples include determining educational or professional goals, juggling various roles of home, school, and work, time management and availability, learning style differences, and "adult pride" in achievement or failure level (p. 69). What mattered most was the willingness (motivation) of the students to communicate their needs and concerns to the instructor, as well as making themselves available to complete tasks online. The weekend master's students also had to adjust learning off-campus, which in itself is an alienating factor. Two of the students, each who flew to Indiana from either Texas or Boston, shared their feelings of disconnectedness from being in an off-campus course, but particularly when coming for the three weekend sessions to a culture and climate decidedly different from their home states.

Based on the pedagogical tenets of learner-centered instruction, courses focused on constructivism, hands-on, and inquiry-based learning - the foundations of an effective classroom - are essential in distant education. When based on these principles, distant education mirrors the effectiveness of traditional education. Among many studies from which to draw, in particular, the results of a study by Cheng, Lehman, and Armstrong (1991) found "no significant difference in the overall course performance or attitudes" between an off-campus class graduate class using computer conferencing and their traditional counterparts on campus.

Another important aspect in developing a successful distance education course is recognizing the unique characteristics of the students, thereby designing instruction to meet their needs. Distance education students differ in learning style from their classroom counterparts, which includes structuring their own learning and having "a higher need and desire for control over their learning environments" (Roblyer, 2003, p. 195). Additionally, distance education learners are generally more abstract learners, have a higher degree of intrinsic motivation, and an internal locus of control. They have been found to have better "test strategies, concentration and time management skills" (Simonson et al, 2003, p. 69) than other learners. Although generally independent learners, distance education students need to feel as though they belong to a unit of some sort - such as a class, cohort, university, small group and so forth. Since many distance education courses are designed for part-time adult learners who are also employed, access must be available to course materials and other resources (Kirkwood \& Price, 2006).

To help relieve the level of anxiety many students incur in distance education courses, greater instructor interaction, availability, and support are needed (Simonson et al, 2003). Instructors can provide a foundation of support and rapport with students by meeting with them in person at the beginning of the course, establishing a two-way communication and thereby avoiding problems later. Kirkwood and Price (2006) describe how the instructor's theory of learning can also affect course delivery and thus students learning, particularly if what they say they believe differs from what they actually do. Using the terms "espoused theory and theory in use" the authors argue that the former theory is that which is believed and said, which may or may not be what they actually do." For example, when using distance technology to replace an on-campus course, the instructor 
may "espouse" that they want students to practice problem solving and inquiry-based learning. Thus, they support an on line course that enables more independent and self-motivated studentthose typically prone to choose an on line course - to work on projects, papers, and assignments within guidelines and parameters to achieve specific goals. However, the instructor may hold the student to narrowly-defined and overly structured formats, requirements, topics, and so forth. In that way, they purport one type of theory of learning and practice the opposite. Failure to recognize the mismatch of paradigms in thought and action will most likely result in student dissatisfaction, lack of engagement, and lack of student success. This is especially important when the learner exists in a "cyber space" classroom and is dependent on a higher degree of autonomy.

Frustrations can also be greater for distance students because they do not witness the vibrancy and excitement of the learning community, as in Purdue's biometric laboratory where real world results are produced. The level of intensity that on-campus students experience is hard to match for distance students, making it difficult for instructors to translate - through technology - the type of learning and expectations that are required. As such, how does technology replace this type of focus? If technologies are to be used purposefully to enhance student learning, they need to be integrated not just in terms of pedagogy, but must also reflect and align with the fundamental educational philosophy and aims. Essentially, as experienced in teaching the distance education students, the authors experienced anecdotal evidence that it came down to student choice, motivation, desire, and goals. The key was to provide students with technology that would facilitate success, was platform neutral, and offered multiple ways of communicating.

\section{Developing the Technology Requirements}

Following the recommendations of the literature, as outlined in the previous section, there were two main issues that the instructor of the course was cognizant of: first was the need for the ability to communicate with the student, and the second was the ability to collaborate. Both had to be done without making the technology overbearing.

Previously, WebCT Vista was used for course management. While this package has several collaborative tools, such as instant messenger chat functions, discussion groups and forums, the disadvantage of these tools is that many times students cannot access WebCT Vista from work. It does not seem to function correctly from behind a corporate firewall and the software times out after a period of inactive use.

At an early stage, it was decided that other tools apart from those embedded in WebCT Vista needed to be investigated. From an instructor's point of view, there needed to be both an administrative and academic functionality.

\section{Instant messenger client requirements}

From an academic/course standpoint, previous experience with students in the Weekend Masters Program showed that students required good instant communication. To satisfy this communication requirement, an instant messenger tool was needed.

Secondly, it is sometimes hard to communicate with individuals through instant messenger clients. Students and faculty may find it hard to communicate effectively through these clients, either because they cannot convey the issue accurately, or they have difficulty typing in sequence. Thus, if an instant messenger client was going to be used, it also required video and/or voice functionality. Again, the requirement was not to overwhelm the student with the technology.

The third requirement was that the instant messenger client should be able to be used on any operating system or computer. As the technology requirements were chosen prior to the start of the cohort, the instructor had no knowledge of the individuals' PC systems. 
The fourth requirement was the ability to communicate with a research group in South Korea, at minimal cost. Again, there was a requirement for a cost-effective solution.

The use of the instant messenger client with video and/or voice capabilities would enhance the communication experience over that of traditional email options. From an academic standpoint this would enable students to communicate with their project members, the team leader (mentor), and the instructor. From an administrative aspect, the use of an instant messenger client enabled students to quickly ping the instructor with a question and get an answer instantly. This would relieve the issue of whether the instructor received an email and the anxiety from the student viewpoint that the instructor might not be as responsive as needed.

When selecting an instant messenger client the following requirements were established:

1. Instant chat functionality

2. Voice capabilities

3. Video capabilities

4. Ability for more than one person to communicate together (both in voice and video)

5. Free (or cheap) calling to a land line if needed

6. Ability for the instant messenger client to work on any operating system

7. Ease to use interface

8. No time out issues (unlike WebCT)

\section{Collaborative software requirements}

While the instructor had used several instant messenger clients (AIM, MSN messenger, Yahoo, Google IM etc.), they had no experience with on-line collaborative tools. Furthermore, the need for a collaborative solution was not realized until after the first weekend, when the course was in session. Primarily the need was observed when one student had problems with document management (which version to use), and the number of attachments that required being emailed. Therefore a needs assessment for collaborative software was rapidly completed in order to place this tool out to the students immediately:

1. Easy to use functionality

2. Ability to see individuals contribution to the document

3. Ability to control document revisions

4. Automatic saving of documents (to remove the issues of 'lost' documents

5. Ability for more than one individual to work on the project at the same time

These requirements for both the instant messenger clients and collaboration tools were updated as the instructors and students gained experience with them.

\section{Selection of the tools}

The instructor therefore chose appropriate tools for the course. For the instant messenger, voice and/or video conferencing tools, Skype was chosen, with Festoon add-in for the video conferencing. For the on line collaborative tools, Writely.com was selected (this software changed midway through the semester to become "Google Doc's and Spreadsheets). 


\section{Exploratory Survey Results}

As part of the evaluation of the communication and collaborative tools, an informal survey was conducted on the cohort. The questions were divided into two parts - the first was concerned with the use of instant messenger client software results, and the second section examined the opinions of the cohort on the use of the collaborative tools.

\section{Instant Messenger Client Survey Results}

At the midpoint of the semester, students $(n=23)$ were surveyed to establish prior use and familiarity with instant messenger clients The first question examined the prior use five popular clients, which included AIM, MSN messenger, Yahoo Instant Messenger, Google Talk; the fifth choice being "other." The most popular instant messenger client was AIM, followed by MSN Messenger, and Yahoo. Several of the students used multiple instant messenger clients, either individually, or through instant messenger aggregating software such as GAIM or Trillian. Skype was not chosen by any student. The goal was to compare the ratings of Skype instant messenger client, as opposed to other instant messenger clients and the degree of satisfaction of Skype.

The first question related to the use of Skype in terms of functionality, SMS text messaging, File Transfer, Chat, and the ability to leave messages. The survey questions were Likert-based, with ranges of "very poor," "poor," "neutral," "good," and "very good."

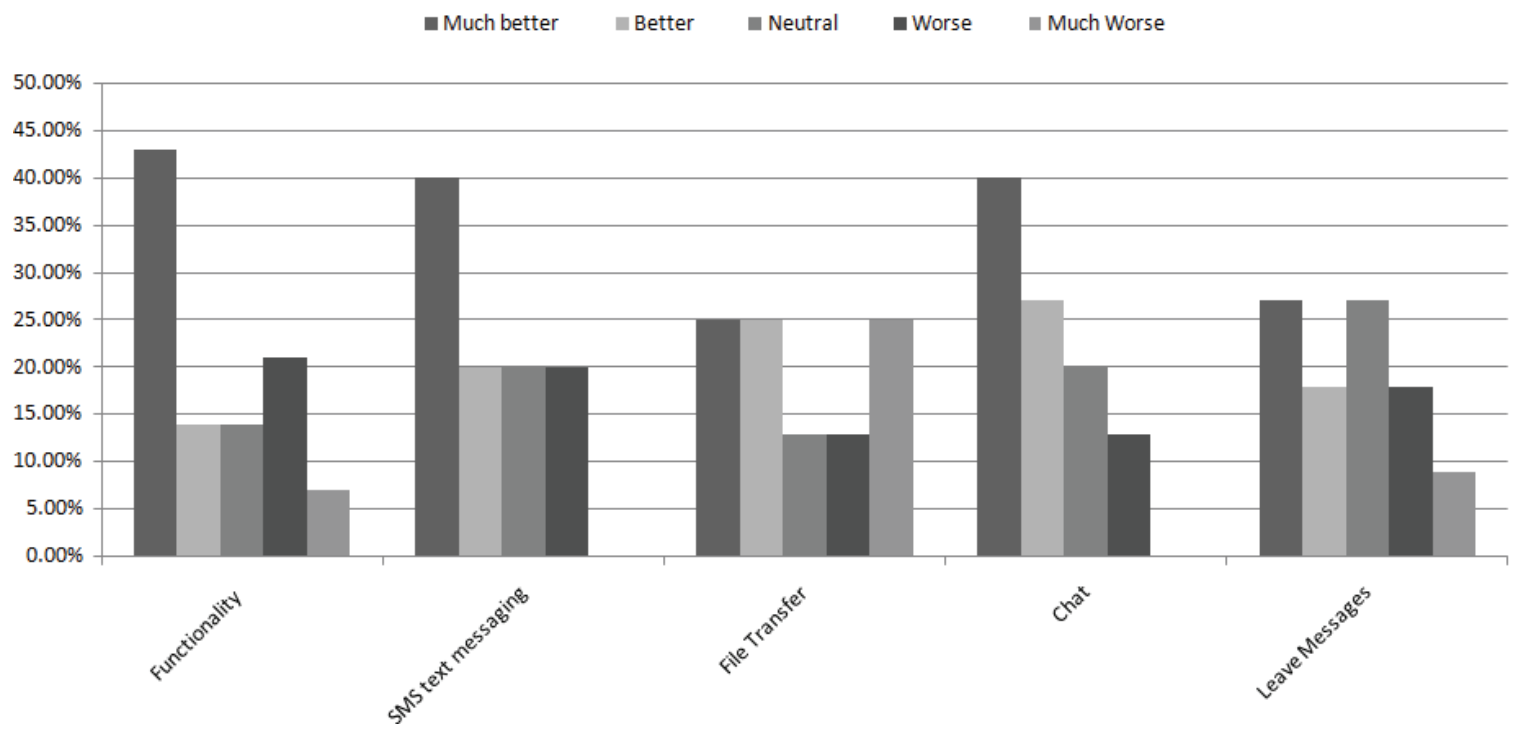

Figure 1: Rate the use of Skype compared to Web CT

The results (Figure 1) show that the vast majority (83\%) of students thought that the functionality of Skype was good or very good, whereas $13 \%$ of respondents were neutral. Similar results were indicated for SMS text messaging. This tool was useful for students to send messages to other students' cell phones. Seventy percent of students rated the use of the file transfer function as "good" or "very good," with the remainder as "neutral." No students rated these functions as "poor" or "very poor." With regards to the chat functionality, 6\% rated the tool as "very poor", but the remainder, 94\%, rated it "good" or "very good." The ratings for the "Leave Messages" function were more dispersed. Ten percent rated it as "poor," $20 \%$ as "neutral," and the remainder as "good" or "very good."

The success of the trial with Skype was the students' ability to adopt this form of communication. Students were asked about their use of Skype for the following scenarios: interaction with the instructor; interaction with their mentor; interaction with group members; interaction with other 
members of the cohort; and interaction with other people outside of the classroom. The questions were asked about their use of Skype as a telephone (Figure 2), the use of Skype/Festoon videoconferencing (see Figure 3), and the use of Skype as a teleconference tool (Figure 4) with each of these various groups.

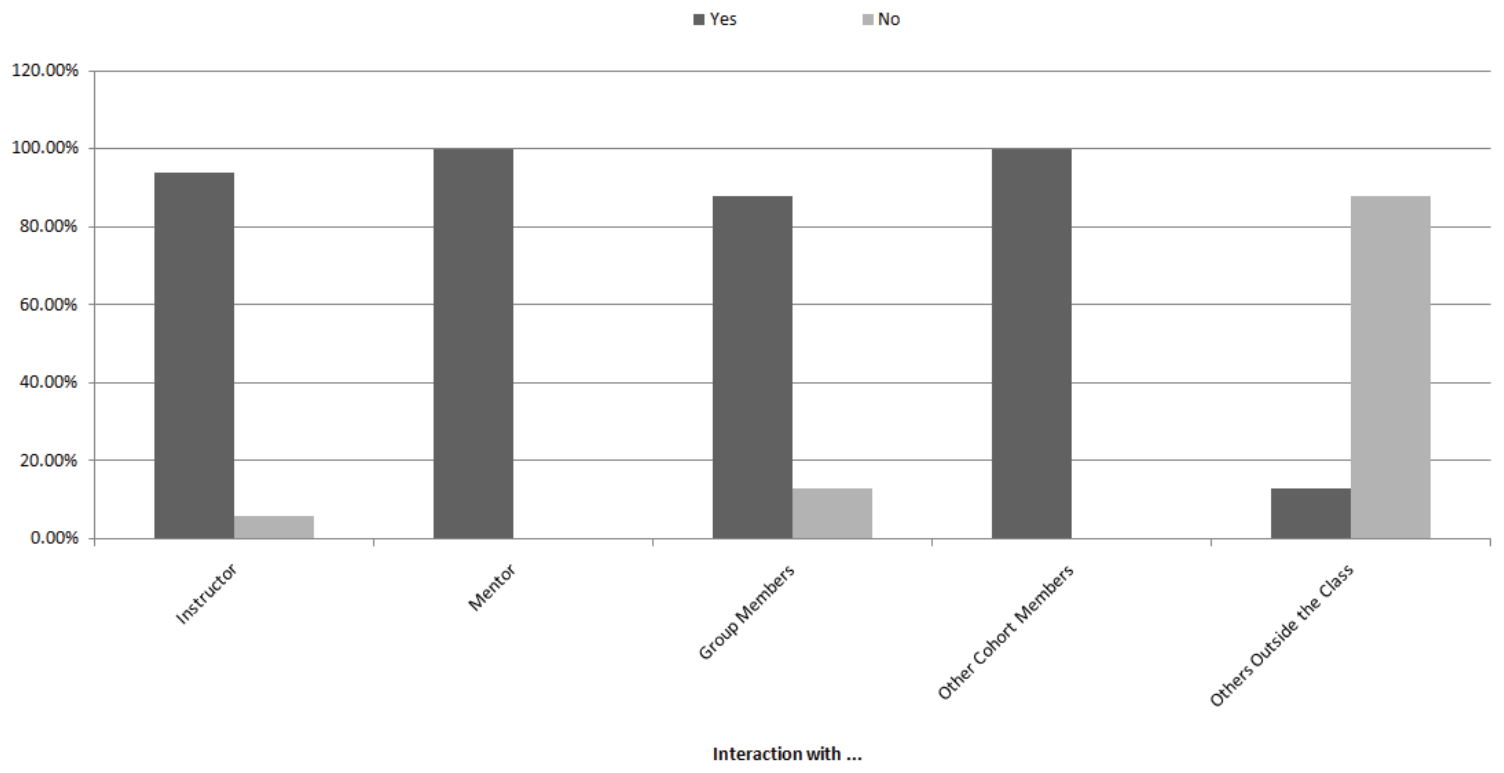

Figure 2: The use of Skype as a phone

From figure 2 above, the students used Skype almost exclusively within the academic environment, but not outside the course. $100 \%$ of the students interacted with their mentor via Skype. This was a good result with regards the development of the communication tool.

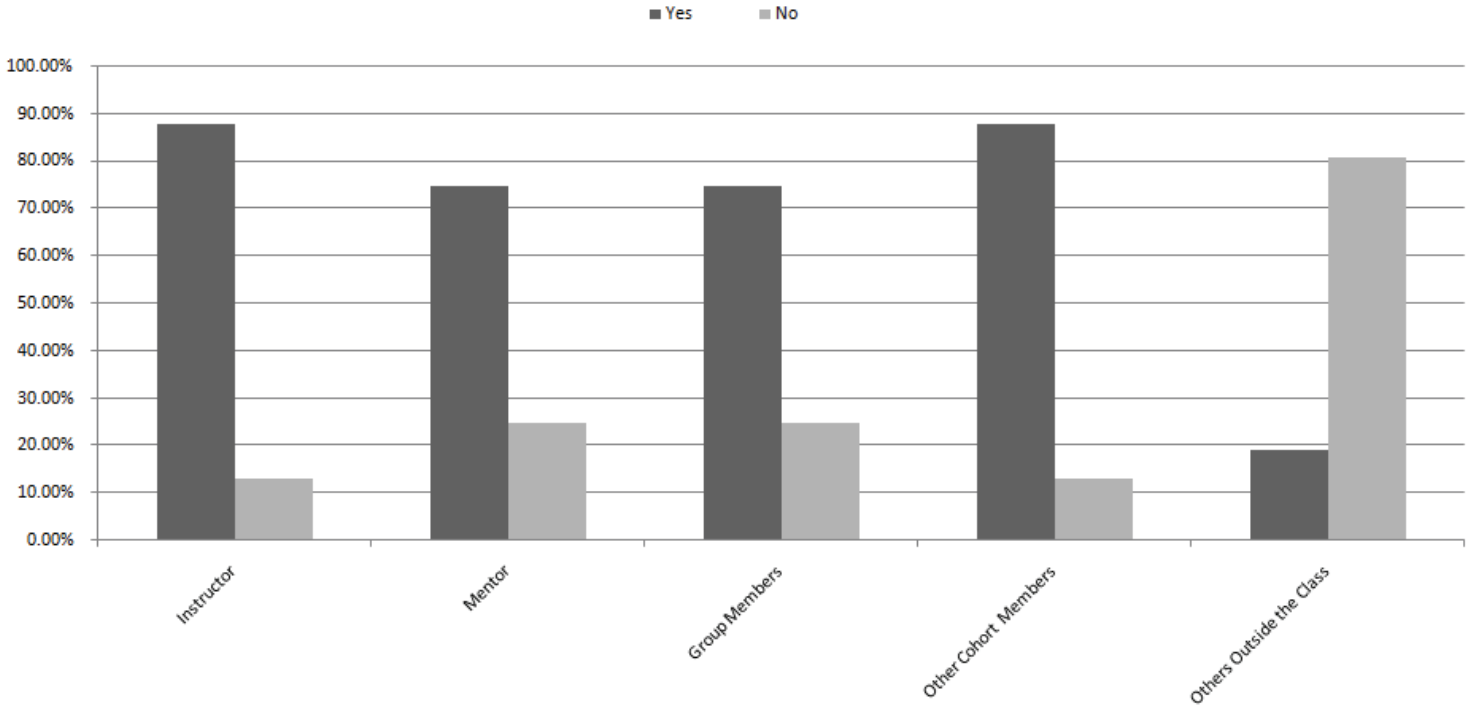

Figure 3: The use of Skype/ Festoon videoconferencing tool

Figure 3 shows similar results to that of Figure 2 when interacting with people in a video conferencing environment. Figure 4 below shows the use of Skype only as a videoconferencing tool. 


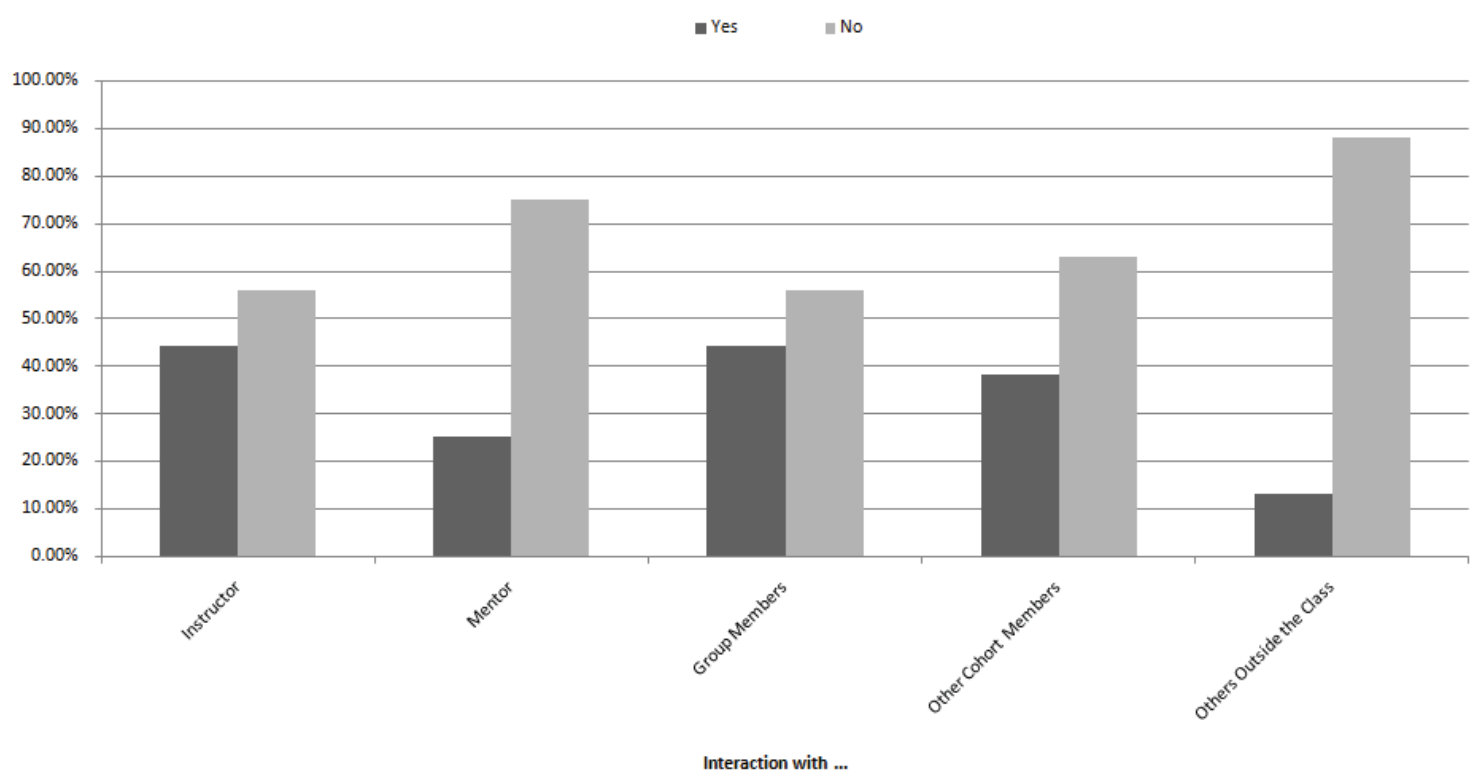

Figure 4: The use of Skype as a teleconference tool

The results in figure 4 show that the use of Skype only as a video-conferencing tool was lower than that of Festoon. Anecdotal evidence shows that students used the Skype/Festoon for one-onone videoconferencing as opposed to the option to do one-on-one videoconferencing with Skype. This observation would only hold for the categories except for "group members".

\section{Collaborative tools survey results}

Although many of the students had interacted with instant messenger software, many (88\%) had no previous experience with collaborative software. Out of those that had used collaborative software or on-line document management collaborative tools, all of them had used the Writely.com software. Figures 5 and 6 show the ratings that the students gave for the on-line collaborative tools. They were asked three questions: the ease of use; the ability to see others work; and the ability not to loose saved work. Again, a five-point Likert scale was used. In Figure 5, there is support for the ease of use and ability to see others work, whereas Figure 6 shows that there were some issues with the tool selected.

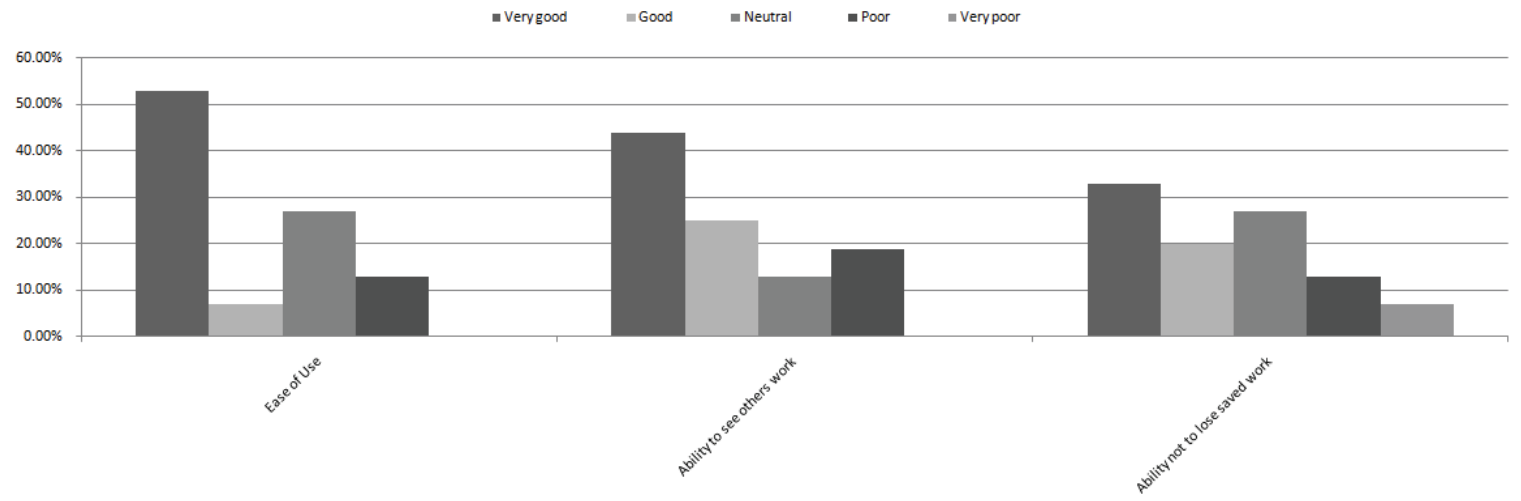

Figure 5: Student rating's of Google Doc's and Spreadsheet 


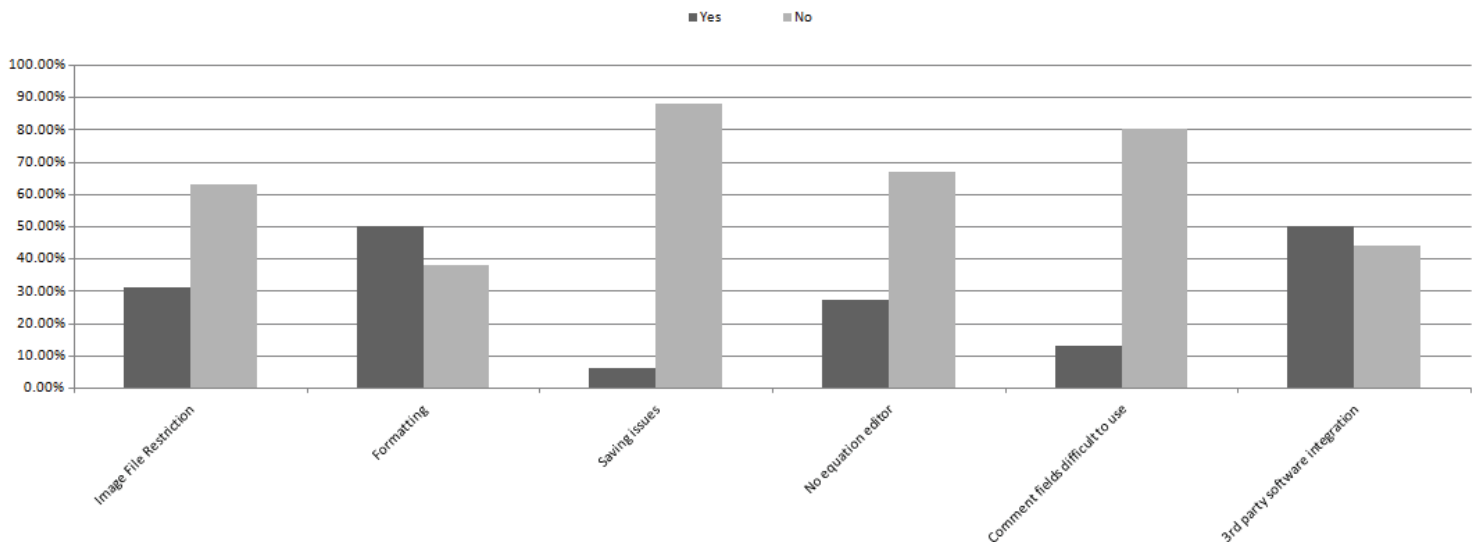

Figure 6: Issues with Google Doc's and Spreadsheets

Figure 6 shows that thirty-one percent of students indicated that there were problems with image file restriction - the software limited the size of images that could be uploaded. This became an issue when uploading statistical charts. Due to the nature of the software, the formatting from Microsoft Word into the collaborative tool did not remain the same. Therefore documents had to be formatted again when they were exported out of the collaborative tool. Fifty percent of the students responded that they had problems with this lack of functionality. Twenty-seven percent of students indicated that they would have liked an equation editor; fifty percent would have liked integration with bibliographic software such as Endnote. From an editorial aspect, comment tables (such as those found in track changes in Microsoft Word) must be completely and manually erased when exported back into the Microsoft Word format.

\section{Conclusion and Lessons Learned}

One of the challenges associated with distance students is to issue the software and have it suitably configured. As each student in this program furnishes their own PC, there is no real opportunity to preload software, or to have a uniform installation procedure. However, the Weekend Masters Program required that students visit campus three times a semester. During their first visit, the students connected to the Internet in the classroom and downloaded Skype Technologies from their website. After testing the software to make sure it worked, the students then loaded the video conferencing tool from Festoon Inc.

Of 23 students enrolled in the course, only one student had an Apple Mac. There were no installation problems with either Skype or Festoon. The students were then given a Logitech web camera from Logitech. There were no installation issues. They then tested the equipment, by dialing "echo123" within Skype. Audio feedback from the microphones onboard the webcams was solved by decreasing the volume on the internal speakers on the laptops - this was also a problem in the first set of group video calls. It was recommended that students have ear-buds or mute their speakers. This software installation protocol will be continued in the Fall 2007 offering of the course.

\section{Instant Messenger Client}

The students seem to have adapted well to the instant messenger client as shown in the exploratory survey results (Figures 2 and 3). The Skype client allows people to send instant messages to those not logged in, which are received once they sign in. Some of the instant messenger clients do not have this functionality. Sometimes students could not download the files from the course companion website, either because they could not remember their password, or could not gain 
access for some other reason. The instant messenger client also has the ability to file share, which was a popular tool to use. The majority of the students have adopted the tool, although the weaker students did not use the tool to communicate with himself or herself or with the instructor. Skype as a one-on-one collaboration tool will be kept for the Fall 2007 course offering. For more than one person (instructor or mentor to student(s)) discussion through video, we will use Adobe Connect (formerly Macromedia Breeze). This provides a lot more functionality for interacting with students. Adobe Connect will replace Festoon for more than one-on-one video.

\section{Collaborative Tools}

For the collaborative tools, we will investigate other options than that of Google Doc's and Spreadsheets. This is primarily due to the formatting required when opening the document in Microsoft Word. Other solutions include examining other Ajax Word Processing tools, such as Zoho Writer, or to look at other non-web based collaborative software, such as Microsoft Groove. While this doesn't provide instantaneous updates, it does provide the student to use Microsoft Word natively. This will be investigated further.

\section{Development of Future Studies}

The authors propose to continue further research into this topic. Obviously technology in collaborative environments is a moving target with respects to new offerings and capabilities. The next study will incorporate newer versions of the technologies listed in this paper, as well as new offerings that are available through the university. This includes evaluating newer Ajax products in a similar vein to that of Google Doc's and Spreadsheets, and traditional Microsoft Office products. We'll also quantitatively examine individual's use of the tools, where possible, through the tools reporting capabilities. Further surveying will occur at the beginning and end of the semester to understand the students learning styles, to see whether they align with that already documented in the literature. The authors will also investigate faculty use of the technology both inside and outside of the classroom. According to Galusha (nd), in a study in Syllabus Magazine (1996) noted that more students owned home computers than faculty at California State University.

Overall, the decision to introduce these technologies was successful, especially the implementation of the instant messenger client. The collaborative document management tool had several advantages over sending out different Microsoft versions via email — so in the case of document revision management, the use of the tool was successful. The same occurred in monitoring the contribution of students to the document management tool - the revision details were wellpresented. The software did not perform as well in the editing and final layout. This prompted the instructor to research other web-based collaborative tools, which will be tested this semester.

\section{References}

Bates, A. W. (1995). Technology, open learning and distance education. London: Routledge.

Cheng, H., Lehman, J., \& Armstrong, P. (1991). Comparison of performance and attitude in traditional and computer conference classes. The American Journal of Distance Education, 5(3), 51-64.

Garland, M.R. (1993). Student perceptions of the situational, institutional, dispositional and epistemological barriers to persistence. Distance Education, 14(2), 181-198.

Galusha, J.M. (n.d.) Barriers to learning in distance education. Retrieved from http://www.infrastruction.com/articles.htm

Kirkwood, A. \& Price, L. (2006). Adaptation for a changing environment: Developing learning and teaching with information and communication technologies. The International Review of Research in Open and Distance Learning, 7(2), ISSN: 1492-3831. Retrieved November 4, 2006 from http://www.irrodl.org/index.php/irrodl/article/view/294/624. 
Roblyer, M.D. (2003). Integrating educational technology into teaching. Upper Saddle River, NJ: Merrill Prentice Hall.

Simonson, M., Smaldino, S., Albright, M., \& Zvacek, S. (2003). Teaching and learning at a distance: Foundations of distance education ( $2^{\text {nd }}$ ed.). Upper Saddle River, NJ: Merrill Prentice Hall.

\section{Biographies}

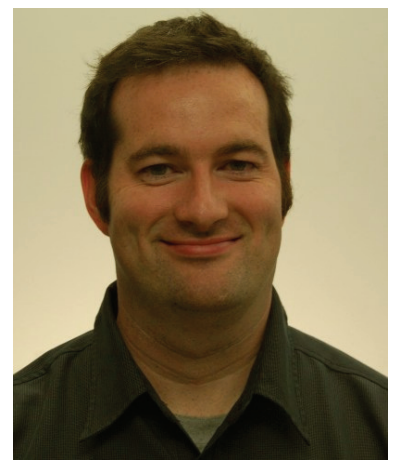

Stephen Elliott, Ph.D. is at Purdue University. Dr. Elliott is involved in a number of activities relating to biometrics and security. He is still actively involved in biometric standards, as the current Secretary of INCITS M1 Biometrics Standards committee as well as being involved in WG5. Dr. Elliott is also involved in educational initiatives as they relate to biometric technologies, where he is responsible for the Biometrics Standards, Performance, and Assurance Laboratory, as well as two classes related to biometric technologies.

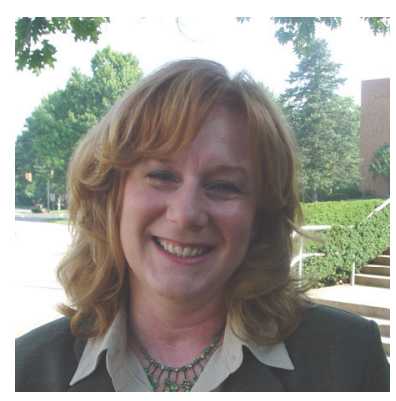

Teresa Rishel, Ph.D. is at Kent State University. Dr. Rishel is an Assistant Professor in Curriculum and Instruction and Middle Childhood Education at Kent State University. She teaches undergraduate and graduate courses in pedagogy, educational theory and multicultural education. She provides expertise in effective teaching methods and strategies, student-centered learning, and inquiry-based instruction. She received her PhD. in Curriculum Studies from Purdue University in 2003. 